\title{
A Comparison of Excessive Drinking, Binge Drinking and Alcohol Dependence in Ethnic Minority Groups in the Netherlands: The HELIUS Study
}

\author{
Jan G.C. van Amsterdam ${ }^{a}$ Annemieke Benschop ${ }^{a}$ Simone van Binnendijk ${ }^{a}$ \\ Marieke B. Snijder $^{b}$ Anja Lok ${ }^{a, b}$ Aart H. Schene ${ }^{c, d}$ Eske M. Derks ${ }^{e}$ \\ Wim van den Brink ${ }^{a}$ \\ a Department of Psychiatry, Academic Medical Center, University of Amsterdam, Amsterdam, The Netherlands; \\ ${ }^{b}$ Department of Public Health, Amsterdam Public Health Research Institute, Academic Medical Center, University \\ of Amsterdam, Amsterdam, The Netherlands; ' ${ }^{C}$ Department of Psychiatry, Radboud University Medical Center, \\ Nijmegen, The Netherlands; ${ }^{d}$ Donders Institute for Brain, Cognition and Behavior, Radboud University, Nijmegen,

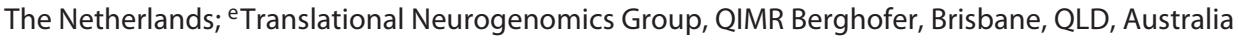

\section{Keywords}

Alcohol dependence $\cdot$ Binge drinking · Depression ·

Ethnicity · Minority $\cdot$ Healthy Life in an Urban Setting study

\begin{abstract}
Background: The Dutch multi-ethnic Healthy Life in an Urban Setting study recently showed that alcohol consumption was lower in ethnic minority groups than those of Dutch origin, but that binge drinking in drinkers of Turkish and Moroccan origin was relatively high. The aim of the current study is to examine factors that may contribute to the differences in drinking patterns and how they relate to the relationship between drinking patterns and alcohol dependence (AD) across ethnic groups. Methods: The rate of last year alcohol use, alcohol use patterns and AD was assessed in 4,635 Dutch, 4,317 Moroccan, 4,036 Turkish, 2,459 Ghanaian, 4,426 African Surinamese and 3,357 South-Asian Surinamese participants (both men and women) born in Amsterdam, the Netherlands. Results: Compared to the Dutch, the prevalence of (regular) drinking is substantially lower in all
\end{abstract}

ethnic minority groups and regular drinkers among most ethnic minority groups have a lower adjusted risk to develop binge drinking and $A D$ than the Dutch. For the prevalence of regular drinking, the ethnic differences are bigger than for the prevalence of current drinking. However, regular drinkers of Moroccan origin have a risk similar to the Dutch to develop binge drinking and $A D$; a finding that could not be explained by group differences in age, sex, religiosity, perceived discrimination, depression or guilt feelings about drinking. Discussion: The prevalence data show that current drinking is lower and that regular drinking is much lower in ethnic minorities and - with the exception of those of Moroccan origin - ethnic minority regular drinkers also have a significant lower risk to develop binge drinking or AD than regular drinkers of Dutch origin. This implies that the magnitude of problematic alcohol use is substantially smaller in ethnic minorities than in the ethnic Dutch population of Amsterdam. Unfortunately, no explanation was found for the special risk situation of regular drinkers of Moroccan origin.

(c) 2019 The Author(s)

Published by S. Karger AG, Basel

\begin{tabular}{ll}
\hline KARGER & (c) 2019 The Author(s) \\
& Published by S. Karger AG, Basel \\
karger@karger.com & This article is licensed under the Creative Commons Attribution- \\
www.karger.com/ear & NonCommercial-NoDerivatives 4.0 International License (CC BY- \\
NC-ND) (http://www.karger.com/Services/OpenAccessLicense). \\
Usage and distribution for commercial purposes as well as any dis- \\
tribution of modified material requires written permission.
\end{tabular}

Dr. Jan G.C. van Amsterdam

Department of Psychiatry, Academic Medical Center

University of Amsterdam

Meibergdreef 5, NL-1105 AZ Amsterdam (The Netherlands)

E-Mail: jan.van.amsterdam@ amsterdamumc.nl; vanamsterdam@ gmx.net 


\section{Introduction}

In the United States, ethnic minority status and ethnic discrimination are associated with an increased prevalence of smoking and drinking [1-5] and increased levels of alcohol consumption [3, 4, 6-8]. Europe is becoming increasingly ethnically diverse and official reports indicate that ethnic minority groups experience discrimination $[9,10]$ in different settings, for example, jobs and housing [11]. However, very little is known about drinking patterns and the presence of alcohol dependence (AD) in ethnic minorities compared to the native population in Europe, including the Netherlands.

In a recent study from the Netherlands it was shown that the association between perceived ethnic discrimination (PED) and alcohol consumption considerably varied by ethnicity. A possible explanation is that different ethnic minority groups might use different strategies to cope with discrimination [12]. Similarly, Dotinga et al. [13, 14] reported that compared to Turks, Moroccans living in the Netherlands showed a higher rate of both alcohol use $(+72 \%)$ and excessive alcohol use (15.4 vs. $5.3 \%$, respectively). Ethnic differences in religiosity are also associated with differences in (heavy or excessive) drinking and $\mathrm{AD}$ $[15,16]$. In addition, it has been shown that the probability of negative consequences (e.g., suicide, ER admission) of drinking are associated with the general level of drinking in a (sub) culture and the level of cultural stigmatization of alcohol use $[17,18]$. This means that not only the prevalence of drinking may differ by culture or ethnic origin, but also the prevalence of heavy or excessive drinking among drinkers, the negative consequences of (excessive) drinking and thus the prevalence of $\mathrm{AD}$ (e.g., [19, 20]). Finally, the persistence of heavy drinking and $A D$ may differ by ethnicities, which - in turn - affect the prevalence of these problems [21-23]. However, in many of these studies, samples were small, non-representative and control for confounders (e.g., discrimination, religiosity) was limited and therefore many of the observed ethnic differences in alcohol use patterns and AD need to be replicated in larger studies with a better control of potential confounders.

In contrast to the study of Visser et al. [12] who investigated cross-ethnic differences in the association of PED with smoking and alcohol consumption, the current study focusses on cross-ethnic differences in the association of excessive drinking and binge drinking with $\mathrm{AD}$ and possible explanations for these differences. Like the study of Visser et al. [12], the current study uses large, representative samples of different ethnic groups from a clearly defined geographic region (Amsterdam, the Netherlands). The aim of this study was to (1) examine the relationship between alcohol use, excessive drinking, binge drinking and AD in regular drinkers; (2) identify the (potential confounding) factors associated with these ethnic differences in alcohol use patterns and AD (including sociodemographic characteristics, perceived discrimination, religiosity, migration generation, and depression); (3), examine factors that may contribute to ethnic differences in the relationship between drinking patterns and $\mathrm{AD}$ in regular drinkers and (4) explain potential differences between ethnic minorities in the risk of regular drinkers to develop AD.

\section{Methods}

\section{Study Population}

We used baseline data from the Healthy Life in an Urban Setting (HELIUS) study, a large, multi-ethnic cohort study in Amsterdam, the Netherlands $[24,25]$. In brief, subjects (18-70 years) were randomly sampled, stratified by ethnicity. Data were collected between 2011 and 2015. The study protocol was approved by the Medical Ethical Review Board, and all participants provided written informed consent. At baseline, 55\% of those invited were contacted, either by response card or after a home visit by an ethnically matched interviewer (contact rate ranged from 46 to $62 \%$ between ethnic groups). Of those contacted, about 50\% agreed to participate (participation rate ranged from 41 to 61\%) [25]. As such, the response rate in the HELIUS study is $28 \%$.

For the current study, we used baseline data of all participants with available questionnaire data $(n=23,942)$. We included all participants with a Dutch $(n=4,635)$, Moroccan $(n=4,317)$, Turkish $(n=4,036)$, Ghanaian $(n=2,459)$, African Surinamese $(n=$ $4,426)$ and South-Asian Surinamese $(n=3,357)$ origin. We excluded participants with a Javanese Surinamese origin $(n=250)$, Surinamese participants of other/unknown ethnic origin $(n=$ $286)$, and participants with another/unknown ethnic origin $(n=$ 50 ), because these groups were too small for the current analyses. Furthermore, 126 participants with missing data on alcohol use were excluded. The initial total sample for this study therefore consisted of 23,230 participants (9,875 males and 13,355 females; Table 1 for samples sizes per ethnic group). Further analyses on excessive drinking, binge drinking and $\mathrm{AD}$ were conducted on a subsample of 7,790 regular drinkers only (4,238 males and 3,552 females; Table 2 for samples sizes per ethnic group). In an attempt to explain differences in the risk to develop $\mathrm{AD}$ among regular drinkers between the different ethnic minority groups, a final analysis of Alcohol Use Disorder Identification Test (AUDIT) item scores (see below) was performed in 2,092 regular drinkers with $\mathrm{AD}$ (1,480 males and 612 females).

\section{Variables}

Ethnicity

Ethnicity was defined according to country of birth of the participants as well as that of his or her parents which is currently the most widely accepted and most valid assessment of ethnicity in the 
Table 1. The prevalence of alcohol use in the last 12 months, by ethnicity

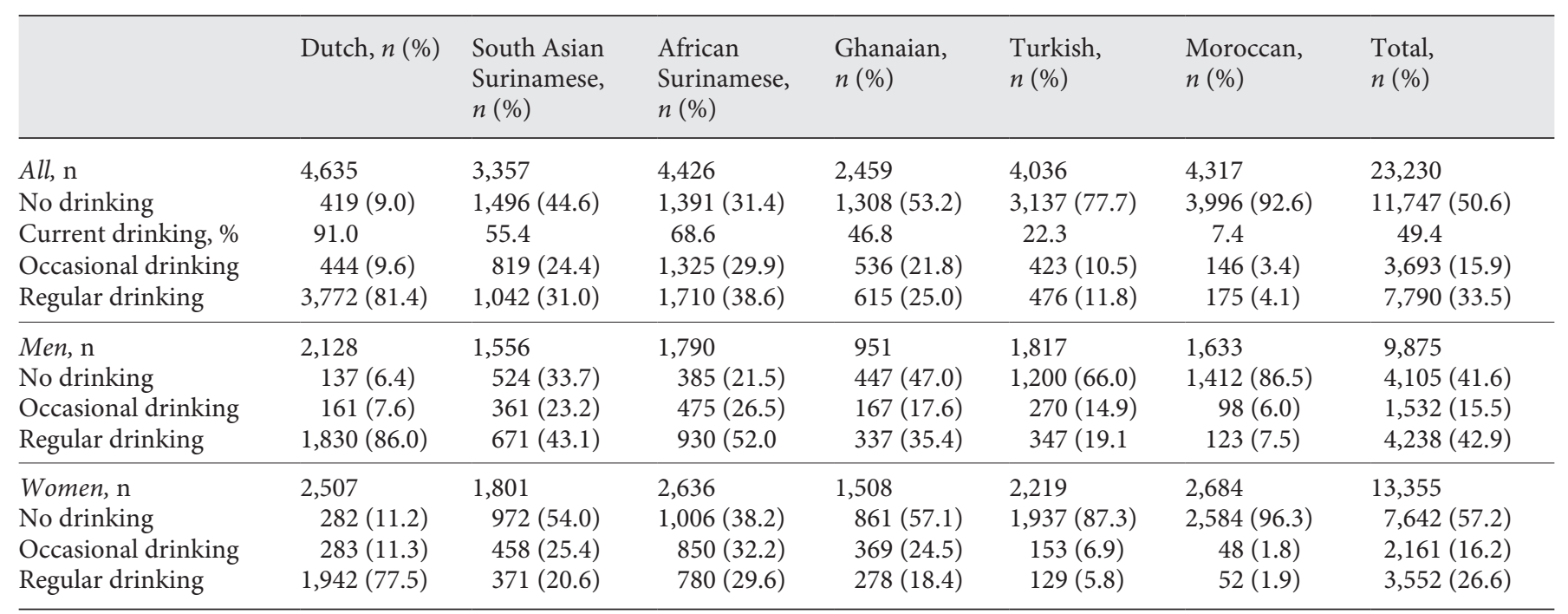

No drinking: no alcohol use; current drinking: using alcohol in the last 12 months; occasional drinking: alcohol use monthly or less; regular drinking: alcohol use at least twice a month.

Table 2. Prevalence of ED, BD and $\mathrm{AD}$ and their mutual ratio's among regular drinkers, by ethnicity

\begin{tabular}{|c|c|c|c|c|c|c|c|}
\hline & $\begin{array}{l}\text { Dutch, } \\
n(\%)\end{array}$ & $\begin{array}{l}\text { South Asian } \\
\text { Surinamese, } \\
n(\%)\end{array}$ & $\begin{array}{l}\text { African } \\
\text { Surinamese, } \\
n(\%)\end{array}$ & $\begin{array}{l}\text { Ghanaian, } \\
n(\%)\end{array}$ & $\begin{array}{l}\text { Turkish, } \\
n(\%)\end{array}$ & $\begin{array}{l}\text { Moroccan, } \\
n(\%)\end{array}$ & $\begin{array}{l}\text { Total, } \\
n(\%)\end{array}$ \\
\hline ED & $754(20.0)$ & $118(11.3)$ & $179(10.5)$ & $42(6.8)$ & $43(9.0)$ & $16(9.1)$ & $1,152(14.8)$ \\
\hline $\mathrm{BD}$ & $1,394(37.0)$ & $309(29.8)$ & $398(23.4)$ & $168(27.5)$ & $173(36.7)$ & $94(53.7)$ & $2,536(32.7)$ \\
\hline $\mathrm{AD}$ & $1,164(30.9)$ & $269(25.9)$ & $290(17.1)$ & $140(23.1)$ & $144(30.6)$ & $85(48.9)$ & $2,092(27.0)$ \\
\hline $\mathrm{BD}$ among $\mathrm{AD}$ & $969(83.2)$ & $203(76.0)$ & $216(74.5)$ & $93(66.9)$ & $116(80.6)$ & $76(89.4)$ & $1,673(80.1)$ \\
\hline $\mathrm{AD}$ among $\mathrm{BD}$ & $969(69.6)$ & $203(66.1)$ & $216(54.8)$ & $93(56.4)$ & $116(67.1)$ & $76(81.7)$ & $1,673(66.3)$ \\
\hline Males, $\mathrm{n}$ & 1,830 & 671 & 930 & 337 & 347 & 123 & 4,238 \\
\hline $\mathrm{ED}$ & $494(27.0)$ & $102(15.2)$ & $146(15.7)$ & $29(8.6)$ & $41(11.8)$ & $13(10.6)$ & 825 (19.5) \\
\hline $\mathrm{BD}$ & 903 (49.4) & $253(37.8)$ & $295(32.0)$ & $110(32.7)$ & $155(45.1)$ & $75(61.0)$ & $1,791(42.4)$ \\
\hline $\mathrm{AD}$ among $\mathrm{BD}$ & $652(72.3)$ & $177(70.0)$ & $165(56.5)$ & $61(55.5)$ & $107(69.0)$ & $64(86.5)$ & $1,226(68.6)$ \\
\hline Females, $\mathrm{n}$ & 1,942 & 371 & 780 & 278 & 129 & 52 & 3,552 \\
\hline ED & $260(13.4)$ & $16(4.3)$ & $33(4.2)$ & $13(4.7)$ & $2(1.6)$ & $3(5.8)$ & $327(9.2)$ \\
\hline $\mathrm{BD}$ & $491(25.3)$ & $56(15.3)$ & $103(13.3)$ & $58(21.1)$ & $18(14.1)$ & $19(36.5)$ & $745(21.1)$ \\
\hline $\mathrm{AD}$ & $424(21.9)$ & $39(10.6)$ & $74(9.6)$ & $47(17.5)$ & $14(11.0)$ & $14(26.9)$ & $612(17.4)$ \\
\hline ED among $\mathrm{AD}$ & $165(38.9)$ & $10(25.6)$ & $25(33.8)$ & $9(19.1)$ & $1(7.1)$ & $2(14.3)$ & $212(34.6)$ \\
\hline $\mathrm{AD}$ among $\mathrm{ED}$ & $165(63.7)$ & $10(66.7)$ & $25(75.8)$ & $9(69.2)$ & $1(50.0)$ & $2(66.7)$ & $212(65.2)$ \\
\hline $\mathrm{BD}$ among $\mathrm{AD}$ & $317(74.8)$ & $26(68.4)$ & $51(68.9)$ & $32(68.1)$ & $9(64.3)$ & $12(85.7)$ & $447(73.2)$ \\
\hline $\mathrm{AD}$ among $\mathrm{BD}$ & $317(64.7)$ & $26(48.1)$ & $51(50.0)$ & $32(58.2)$ & $9(50.0)$ & $12(63.2)$ & $447(60.6)$ \\
\hline
\end{tabular}

ED: at least 3-4 glasses of alcohol per day, at least 4 times per week; BD: at least 6 glasses of alcohol per occasion, at least once a month; AD: AUDIT sum score $\geq 8$.

$\mathrm{ED}$, excessive drinking; $\mathrm{BD}$, binge drinking; $\mathrm{AD}$, alcohol dependent; AUDIT, Alcohol Use Disorder Identification Test. 
Netherlands [26]. Specifically, a participant was considered of non-Dutch ethnicity if either of the following criteria was fulfilled: (1) born outside the Netherlands and at least 1 parent born outside the Netherlands (i.e., first generation); or (2) born in the Netherlands, but at least 1 parent born outside the Netherlands (i.e., second generation). Participants of Surinamese origin were further subdivided (through self-reported ethnicity) into the following subgroups: African, South-Asian, Javanese or other/unknown Surinamese origin.

\section{Alcohol Use (Time Frame of Last 12 Months Applies to All)}

For alcohol use prevalence, we used data from the following question regarding alcoholic drinking in the past 12 months: "How often do you have a drink that contains alcohol" with the following answer categories: not in the past 12 months, but have done so before this, never, once or less monthly, 2-4 times monthly, 2-3 times weekly, 4 times or more weekly. Occasional drinking was defined as drinking alcohol monthly or less; regular drinking was defined as drinking alcohol at least twice a month. Excessive drinking was determined by asking how often 1 drinks alcoholic beverages in combination with how many glasses 1 drinks on a typical day of drinking. Drinking of alcoholic beverages "at least 4 times a week" combined with "at least 3-4 glasses per day" was considered excessive drinking $(y / n)$. The cut-offs for excessive drinking were based on the Netherlands Mental Health Survey and Incidence Study-2 [27]. This measure does not necessarily include binge drinking. Therefore, binge drinking was defined as the consumption of 6 or more drinks per occasion at least once a month, and determined by asking how often do you drink 6 or more glasses per occasion? The 5 answer categories were as follows: never, less than monthly, monthly, weekly, and daily or almost daily.

\section{Alcohol Dependence}

$\mathrm{AD}$ was determined by the AUDIT-10 [28], which consists of ten questions (e.g., "how often during the last year have you failed to do what was normally expected from you because of drinking"). The sum score varied from 0 to 40 , with a score $\geq 8$ for determining $\mathrm{AD}[28,29]$. If only 1 item was missing, the mean score of the other nine items was used to substitute the missing item. If more than 1 item was missing, the AUDIT was not calculated and considered missing. A lower cut-off for women (i.e., score $\geq 6$ ) did not affect the results. Special attention in the analysis was dedicated to item 7 of the AUDIT-10 about feelings of guilt and remorse related to alcohol abuse. The AUDIT is a screening instrument, and thus provides a proxy for $\mathrm{AD}$ or alcohol use disorder.

\section{Covariates}

Sociodemographic information was obtained by questionnaire and included age, sex and marital status (3 categories: never married; married/living with a partner; divorced/widowed). Other characteristics that were used as covariates in the regression analyses were educational level, employment status, religiosity, PED, migration generation, and depressed mood. Educational level was defined as the highest level of education completed, either in the Netherlands or in the country of origin: no education or elementary education; lower vocational or lower secondary education; intermediate vocational or intermediate/higher secondary education; and higher vocational education or university. For employment status we used the following categories: employed; unemployed (seeking work/in welfare); not in the labour force. With regard to religiosity, participants were asked whether they were raised religiously and whether they are practicing a specific religion. Four categories of religiosity were derived: non-religious; raised religiously, currently non-religious; currently religious, non-practicing (i.e., has not visited a place of worship in the past 6 months); currently practicing religious. PED was conceptualized as the day-to-day experiences of unfair treatment (both overt and subtle) because of ethnic background [30]. For further details about PED assessment see Ikram et al. [9]. Finally, depressed mood was measured using the Patient Health Questionnaire-9 with a cut-off score of 10 .

\section{Statistical Analyses}

Ethnic group differences in alcohol use, excessive drinking, binge drinking and $\mathrm{AD}$ were examined using chi-square and Fisher Exact tests. In logistic regression analyses, ORs were calculated for excessive drinking, binge drinking and $\mathrm{AD}$ by ethnicity, with the Dutch sample serving as the reference group. Five models were explored in the regression analyses. Model 1 was the unadjusted model. In model 2, we adjusted for sex (total sample only) and age, in model 3 we additionally adjusted for marital status, educational level and employment status. In the Dutch subgroup, migration generation was not applicable and very few of were religious or PED. We therefore excluded Dutch participants and made drinkers of Moroccan origin the reference group in model 4 with additional adjustment for religiosity, migration generation and PED. In model 5 (again without the Dutch participants and participants of Moroccan origin as the reference group), we additionally adjusted for depressed mood. To reduce the number of parameters in the analyses, multi-categorical covariates were transformed into binary variables according to the coding schedule depicted by the square brackets ([0] and [1]) in Tables 3 and 4. All statistical analyses were performed using IBM SPSS Statistics version 25 .

\section{Results}

\section{Patterns of Drinking across Different Ethnic Groups}

Table 1 shows that the highest rates of current drinking and regular drinking were observed in the Dutch participants ( 91.0 and $81.4 \%$ respectively) with relatively low rates of occasional drinking (9.6\%). Much lower rates of current drinking and regular drinking were observed in all ethnic minority groups, especially in the 2 ethnic minority groups with a predominant Muslim background: Turks with rates of 22.3 and $11.8 \%$ and Moroccans with rates of 7.4 and $4.1 \%$ for current drinking and regular drinking respectively. In addition to the expected lower prevalence of current drinking in ethnic groups, we found an even bigger difference between the Dutch and ethnic groups in the prevalence of regular drinking (cf. Table 1). The figures about current drinking confirm those previously found by Visser et al. [12]. As expected, and related 
Table 3. Demographic characteristics of regular drinkers

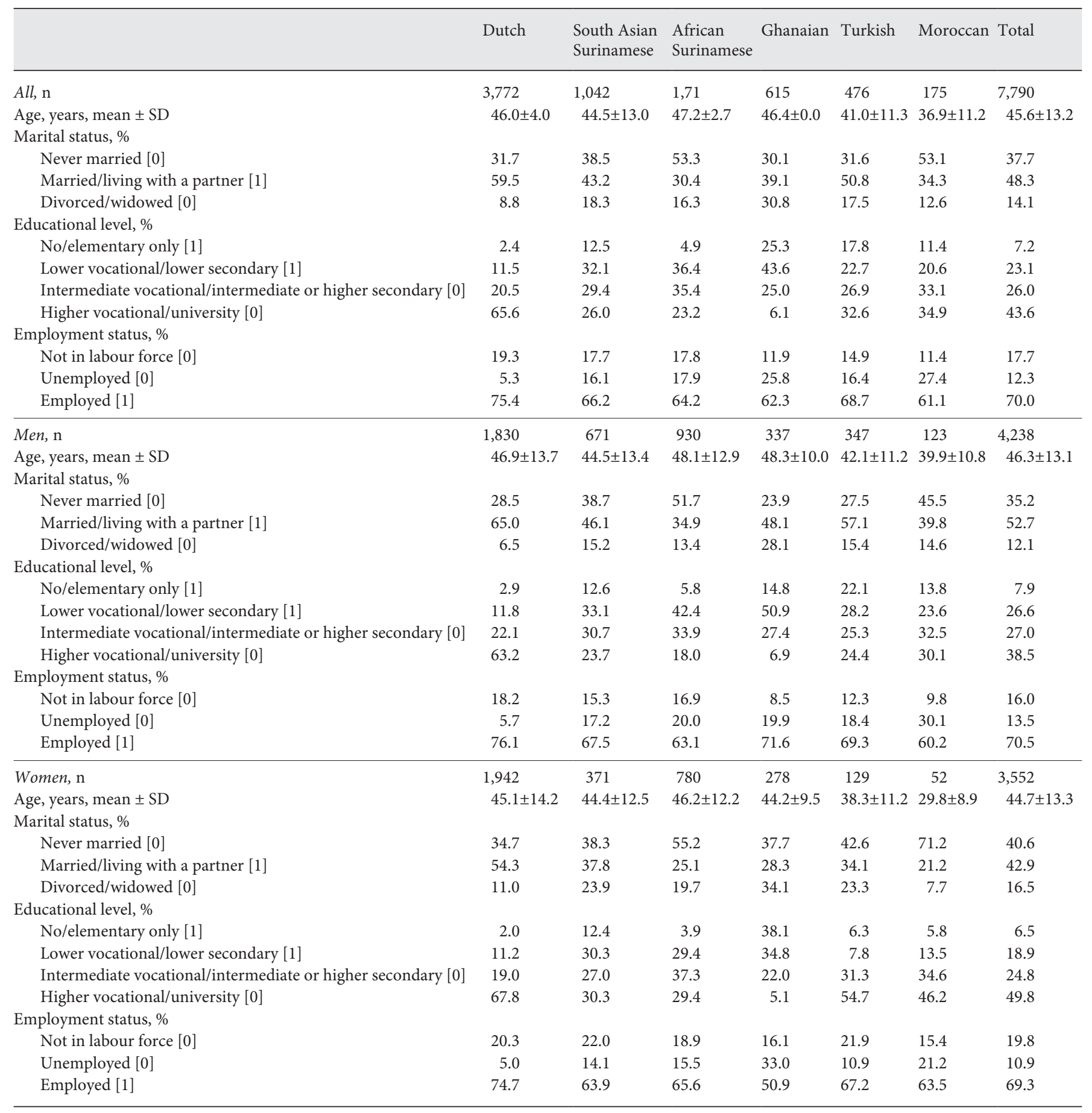

to the Muslim background, full abstinence from drinking alcohol was high across participants of Turkish and Moroccan origin (77.7 and $92.6 \%$, respectively), whereas in the 3 other ethnic minority groups the rate of non-drinkers was moderate, but consistently higher than in the
Dutch origin group. Overall, women were less likely to consume alcohol than men. Especially, very few women of Turkish and Moroccan origin were occasional or regular drinkers (1.8-6.9\%). 
Table 4. Religiosity, migration generation, perceived discrimination and depressed mood in regular drinkers, by ethnicity

\begin{tabular}{|c|c|c|c|c|c|c|c|}
\hline & Dutch & $\begin{array}{l}\text { South Asian } \\
\text { Surinamese }\end{array}$ & $\begin{array}{l}\text { African } \\
\text { Surinamese }\end{array}$ & Ghanaian & Turkish & Moroccan & Total \\
\hline All, $\mathrm{n}$ & 3,772 & 1,042 & 1,710 & 615 & 476 & 175 & 7,790 \\
\hline Non-religious [0] & 55.9 & 12.9 & 13.4 & 2.9 & 16.3 & 1.1 & 33.2 \\
\hline Raised religiously, currently non-religious [0] & 33.0 & 15.9 & 16.4 & 14.9 & 17.0 & 18.4 & 24.5 \\
\hline Currently religious, non-practicing $[0]$ & 4.1 & 32.2 & 29.5 & 4.8 & 28.0 & 44.3 & 15.8 \\
\hline \multicolumn{8}{|l|}{ Migration, $\%$} \\
\hline First-generation migrant [1] & NA & 71.4 & 80.4 & 96.4 & 65.1 & 54.9 & 40.0 \\
\hline Second-generation migrant $[0]$ & NA & 28.6 & 19.6 & 3.6 & 34.9 & 45.1 & 11.6 \\
\hline Perceived ethnic discrimination score, mean \pm SD & $1.1 \pm 0.3$ & $2.0 \pm 0.8$ & $2.1 \pm 0.8$ & $2.0 \pm 0.8$ & $1.9 \pm 0.7$ & $2.0 \pm 0.7$ & $1.6 \pm 0.7$ \\
\hline Depressed mood (PHQ-9 10+), \% & 5.9 & 16.3 & 9.8 & 10.2 & 21.4 & 27.4 & 9.9 \\
\hline Men, $\mathrm{n}$ & 1,830 & 671 & 930 & 337 & 347 & 123 & 4,238 \\
\hline \multicolumn{8}{|l|}{ Religiosity, \% } \\
\hline Currently practicing religious [1] & 6.5 & 41.4 & 37.6 & 74.6 & 46.7 & 45.1 & 28.5 \\
\hline \multicolumn{8}{|l|}{ Migration, $\%$} \\
\hline First-generation migrant [1] & NA & 72.3 & 82.0 & 96.7 & 68.9 & 65.0 & 44.7 \\
\hline Second-generation migrant $[0]$ & NA & 27.7 & 18.0 & 3.3 & 31.1 & 35.0 & 12.2 \\
\hline Perceived ethnic discrimination score, mean \pm SD & $1.1 \pm 0.3$ & $2.0 \pm 0.8$ & $2.2 \pm 0.8$ & $2.0 \pm 0.8$ & $2.0 \pm 0.7$ & $2.1 \pm 0.8$ & $1.7 \pm 0.8$ \\
\hline Depressed mood (PHQ-9 10+), \% & 4.8 & 14.1 & 6.3 & 8.7 & 20.7 & 24.4 & 8.8 \\
\hline Women, $\mathrm{n}$ & 1,942 & 371 & 780 & 278 & 129 & 52 & 3,552 \\
\hline \multicolumn{8}{|l|}{ Religiosity, \% } \\
\hline Non-religious [0] & 55.6 & 13.4 & 12.4 & 2.7 & 26.2 & 1.9 & 36.1 \\
\hline Raised religiously, currently non-religious [0] & 32.5 & 15.3 & 14.0 & 12.1 & 22.2 & 25.0 & 24.7 \\
\hline Currently religious, non-practicing $[0]$ & 4.4 & 36.7 & 29.2 & 4.3 & 34.1 & 57.7 & 15.1 \\
\hline
\end{tabular}

PHQ-9, Patient Health Questionnaire-9; NA, not applicable.

Relationship between Alcohol Use, Excessive Drinking, Binge Drinking and $A D$

Considering that the differences between the regular drinking Dutch and the ethnic groups are bigger for regular drinking than for current drinking, we further focussed on regular drinkers. The prevalence rates of excessive drinking, binge drinking and $\mathrm{AD}$ among regular drinkers are depicted in Table 2. Rates of excessive drinking among regular drinkers were consistently lower in all 5 ethnic minority groups compared to the Dutch (6.8-11.3 vs. $20.0 \%$, respectively). Similarly, the rates of both binge drinking and $\mathrm{AD}$ among regular drinkers of Surinamese, Ghanaian and Turkish origin were also lower than the Dutch, but regular drinkers of Moroccan origin showed a 1.5-1.6 times higher rate than those of Dutch origin for both binge drinking and AD. Table 2 further shows that the proportion of excessive drinkers (14-46\%) is lower than the proportion of binge drinkers (67-89\%) among alcohol dependent subjects.

\section{Confounding of the Relation between Ethnicity with}

Alcohol Use Patterns and AD

Participants of Moroccan origin showed some demographic characteristics deviant from the other 5 ethnic subgroups studied as they were relatively young, more 
frequently unemployed, relatively highly educated (except as compared with the Dutch), and more often single (never married; cf. Table 3). Furthermore, of all ethnic minority groups, those of Moroccan origin showed the highest prevalence of depressed mood, were in general more religious, and were more often a second-generation migrant (cf. Table 4). Given these group differences, adjusted risk ratios need to be calculated using different models with different sets of (potential) confounders.

Table 5 depicts the results of the unadjusted (model 1) and adjusted (models 2-5) analyses. All 5 ethnic minority groups show significantly lower rates of excessive drinking in regular drinkers compared to regular drinkers of Dutch origin (ORs $<1.00)$, independent of adjustment for potential confounders (model 2-3) and with no significant differences among the different ethnic minorities (models 4-5). Similarly, but with the exception of those of Moroccan origin, regular drinkers belonging to ethnic minority groups also show significantly lower rates of both binge drinking and $\mathrm{AD}$ compared to regular drinkers of Dutch origin (ORs $<1.00)$. With respect to binge drinking and $\mathrm{AD}$, regular drinkers of Moroccan origin (men not women) show a higher rate than the Dutch, but the difference was no longer statistically significant after adjustment for confounders (ORs not significantly different from 1.00 in models 3-5).

\section{Differences between Ethnic Minorities in the Risk to \\ Develop $A D$}

We further explored why male regular drinkers of Moroccan origin have a similar risk of developing AD compared to their Dutch peers, whereas regular drinkers in the other 4 ethnic minority groups (men and women) showed a significantly lower risk for $\mathrm{AD}$, we performed a sub-analysis using the response to item 7 of the AUDIT-10 ("feeling of guild or remorse") since male regular drinking of Moroccan origin with AD scored relatively high on this item: Moroccans $1.8 \pm 1.5 ; n=71$; Dutch $1.0 \pm 1.0 ; n=740$; South Asian Surinamese $1.0 \pm$ 1.2; $n=230$; African Surinamese $1.0 \pm 1.3 ; n=216$; Ghanaians $1.3 \pm 1.4 ; n=93$; Turks $1.2 \pm 1.4 ; n=130(p<$ 0.001 ). After exclusion of this item from the AUDIT sum score (leaving a cut-off score of 7 instead of 8 for AD), an additional regression analysis was performed with males from all ethnic groups and using the covariates of model 3 (age, marital status, educational level and employment status). Results from this analysis suggested that the risk of developing $\mathrm{AD}$ (without guilt/remorse as an AD crite- rion) among male regular drinkers of Moroccan origin is still similar to that among their Dutch peers, but significantly higher than among the other 4 ethnic minority groups: OR compared to Dutch: South Asian Surinamese 0.61 (0.50-0.74), African Surinamese 0.41 (0.34-0.49), Ghanaians $0.46(0.35-0.60)$, Turks 0.62 (0.48-0.80), Moroccans 1.29 (0.88-1.9); Nagelkerke $R^{2}=0.078$. A subsequent analysis with additional adjustment for religiosity, migration generation, PED and depressed mood (similar to model 5) still indicated a higher risk of developing AD among males of Moroccan origin compared to the other ethnic minority groups: OR compared to Moroccans: South-Asian Surinamese 0.48 (0.32-0.72), African Surinamese 0.31 (0.21-0.47), Ghanaians 0.37 (0.24-0.59), Turks 0.49 (0.31-0.76; Nagelkerke $\left.R^{2}=0.101\right)$. The AUDIT-item "feelings of guilt" proved to be the only item on which Moroccans scored differently from all other ethnic groups. However, excluding the item "feeling of guild or remorse" therefore did not change the general results.

\section{Discussion}

The current study shows that compared to the Dutch, the prevalence of current drinking and regular drinking is substantially lower in the 5 ethnic minority groups studied in Amsterdam. It appeared that the differences between the Dutch and the ethnic groups with respect to the prevalence of regular drinking are considerably bigger than for current drinking. Focussing on regular drinkers, we extended the previous findings of Visser et al. [12] obtained in current drinkers.

Except for those of Moroccan origin, regular drinkers among ethnic minority groups have a much lower risk to develop problematic alcohol use, including binge drinking and $\mathrm{AD}$. With respect to $\mathrm{AD}$, similar results have been previously obtained in current drinkers [12]. These differences remain after controlling for potential confounders. Remarkably, regular drinkers of Moroccan origin have a risk to develop AD similar to their Dutch peers; a finding that could not be explained by ethnic group differences in important variables like group differences in age, sex, religiosity, perceived discrimination, depression and/or guilt feelings about drinking.

Members of the ethnic minority groups in Amsterdam, in particular people of Turkish and Moroccan origin, are not only more often teetotallers but are even less frequently regular drinkers than those of Dutch origin. In addition, the prevalence of occasional and regular
72

Eur Addict Res 2020;26:66-76 DOI: $10.1159 / 000504881$ van Amsterdam et al. 
Table 5. ORs (95\% CI) for $\mathrm{ED}, \mathrm{BD}$ and $\mathrm{AD}$ in regular drinkers

\begin{tabular}{|c|c|c|c|c|c|c|c|}
\hline & Dutch & South Asian Surinamese & African Surinamese & Ghanaian & Turkish & Moroccan & Nagelkerke $R^{2}$ \\
\hline All, $\mathrm{n}$ & 3,772 & 1,042 & 1,710 & 615 & 476 & 175 & \\
\hline \multicolumn{8}{|l|}{ ED } \\
\hline Model 1 & 1 & $0.51(0.41-0.63)$ & $0.47(0.39-0.56)$ & $0.32(0.23-0.44)$ & $0.39(0.28-0.54)$ & $0.40(0.24-0.68)$ & 0.037 \\
\hline Model 2 & 1 & $0.46(0.37-0.57)$ & $0.41(0.34-0.50)$ & $0.28(0.20-0.39)$ & $0.37(0.26-0.52)$ & $0.43(0.25-0.73)$ & 0.120 \\
\hline Model 3 & 1 & $0.43(0.34-0.54)$ & $0.37(0.31-0.45)$ & $0.26(0.18-0.37)$ & $0.35(0.25-0.49)$ & $0.38(0.23-0.66)$ & 0.126 \\
\hline Model 4 & - & $1.21(0.68-2.14)$ & $1.04(0.60-1.83)$ & $0.72(0.38-1.35)$ & $0.97(0.52-1.81)$ & 1 & 0.107 \\
\hline Model 5 & - & $1.25(0.71-2.22)$ & $1.12(0.63-1.97)$ & $0.76(0.40-1.44)$ & $0.98(0.52-1.84)$ & 1 & 0.109 \\
\hline \multicolumn{8}{|l|}{$\mathrm{BD}$} \\
\hline Model 1 & 1 & $0.73(0.63-0.85)$ & $0.52(0.46-0.59)$ & $0.63(0.52-0.77)$ & $0.99(0.81-1.21)$ & $2.00(1.47-2.71)$ & 0.027 \\
\hline Model 2 & 1 & $0.55(0.47-0.64)$ & $0.48(0.42-0.55)$ & $0.57(0.47-0.71)$ & $0.62(0.50-0.77)$ & $1.19(0.87-1.64)$ & 0.161 \\
\hline Model 3 & 1 & $0.45(0.38-0.54)$ & $0.39(0.33-0.45)$ & $0.43(0.34-0.53)$ & $0.52(0.42-0.65)$ & $1.01(0.73-1.40)$ & 0.173 \\
\hline Model 4 & - & $0.39(0.28-0.55)$ & $0.30(0.22-0.42)$ & $0.36(0.24-0.52)$ & $0.50(0.34-0.72)$ & 1 & 0.136 \\
\hline Model 5 & - & $0.41(0.29-0.57)$ & $0.32(0.23-0.46)$ & $0.38(0.26-0.56)$ & $0.50(0.35-0.73)$ & 1 & 0.139 \\
\hline \multicolumn{8}{|l|}{$\mathrm{AD}$} \\
\hline Model 1 & 1 & $0.78(0.66-0.91)$ & $0.46(0.40-0.53)$ & $0.66(0.53-0.81)$ & $0.98(0.79-1.21)$ & $2.14(1.58-2.91)$ & 0.032 \\
\hline Model 2 & 1 & $0.62(0.53-0.73)$ & $0.43(0.37-0.50)$ & $0.61(0.49-0.75)$ & $0.68(0.55-0.85)$ & $1.46(1.06-2.00)$ & 0.116 \\
\hline Model 3 & 1 & $0.51(0.43-0.61)$ & $0.34(0.29-0.40)$ & $0.47(0.37-0.59)$ & $0.59(0.47-0.74)$ & $1.20(0.87-1.66)$ & 0.133 \\
\hline Model 4 & - & $0.39(0.28-0.56)$ & $0.24(0.17-0.35)$ & $0.37(0.25-0.54)$ & $0.47(0.32-0.69)$ & 1 & 0.160 \\
\hline Model 5 & - & $0.42(0.29-0.60)$ & $0.28(0.19-0.40)$ & $0.42(0.28-0.62)$ & $0.48(0.33-0.71)$ & 1 & 0.172 \\
\hline Men, $\mathrm{n}$ & 1,830 & 671 & 930 & 337 & 347 & 123 & \\
\hline \multicolumn{8}{|l|}{$\mathrm{ED}$} \\
\hline Model 1 & 1 & $0.49(0.39-0.62)$ & $0.51(0.41-0.62)$ & $0.26(0.18-0.39)$ & $0.35(0.25-0.50)$ & $0.32(0.18-0.58)$ & 0.048 \\
\hline Model 2 & 1 & $0.52(0.41-0.66)$ & $0.48(0.39-0.59)$ & $0.25(0.17-0.38)$ & $0.42(0.29-0.60)$ & $0.40(0.22-0.73)$ & 0.086 \\
\hline Model 3 & 1 & $0.46(0.35-0.59)$ & $0.41(0.32-0.51)$ & $0.22(0.14-0.33)$ & $0.37(0.26-0.54)$ & $0.35(0.19-0.63)$ & 0.095 \\
\hline Model 4 & - & $1.42(0.76-2.66)$ & $1.22(0.66-2.28)$ & $0.67(0.33-1.37)$ & $1.15(0.59-2.28)$ & 1 & 0.068 \\
\hline Model 5 & - & $1.47(0.78-2.77)$ & $1.31(0.70-2.46)$ & $0.71(0.34-1.45)$ & $1.16(0.59-2.30)$ & 1 & 0.070 \\
\hline \multicolumn{8}{|l|}{$\mathrm{BD}$} \\
\hline Model 1 & 1 & $0.64(0.53-0.77)$ & $0.49(0.41-0.58)$ & $0.49(0.38-0.63)$ & $0.85(0.67-1.08)$ & $1.64(1.13-2.39)$ & 0.036 \\
\hline Model 2 & 1 & $0.58(0.48-0.70)$ & $0.49(0.42-0.59)$ & $0.50(0.39-0.65)$ & $0.72(0.57-0.92)$ & $1.34(0.92-1.97)$ & 0.084 \\
\hline Model 3 & 1 & $0.49(0.40-0.59)$ & $0.40(0.33-0.48)$ & $0.39(0.30-0.51)$ & $0.61(0.47-0.78)$ & $1.15(0.78-1.70)$ & 0.096 \\
\hline Model 4 & - & $0.40(0.26-0.59)$ & $0.29(0.20-0.44)$ & $0.31(0.20-0.48)$ & $0.54(0.35-0.83)$ & 1 & 0.059 \\
\hline Model 5 & - & $0.41(0.27-0.62)$ & $0.32(0.21-0.48)$ & $0.33(0.21-0.52)$ & $0.54(0.35-0.83)$ & 1 & 0.066 \\
\hline \multicolumn{8}{|l|}{$\mathrm{AD}, \mathrm{n}$} \\
\hline Model 1 & 1 & $0.77(0.64-0.92)$ & $0.45(0.37-0.54)$ & $0.55(0.42-0.72)$ & $0.90(0.70-1.14)$ & $2.09(1.43-3.03)$ & 0.039 \\
\hline Model 2 & 1 & $0.72(0.60-0.87)$ & $0.45(0.38-0.55)$ & $0.57(0.43-0.74)$ & $0.80(0.62-1.02)$ & $1.80(1.23-2.62)$ & 0.064 \\
\hline Model 3 & 1 & $0.59(0.48-0.72)$ & $0.35(0.29-0.43)$ & $0.44(0.34-0.58)$ & $0.66(0.51-0.85)$ & $1.46(0.99-2.15)$ & 0.084 \\
\hline Model 4 & - & $0.38(0.26-0.58)$ & $0.21(0.14-0.32)$ & $0.29(0.18-0.46)$ & $0.46(0.30-0.72)$ & 1 & 0.108 \\
\hline Model 5 & - & $0.40(0.27-0.61)$ & $0.24(0.16-0.36)$ & $0.32(0.20-0.51)$ & $0.46(0.29-0.72)$ & 1 & 0.123 \\
\hline Women & 1,942 & 371 & 780 & 278 & 129 & 52 & \\
\hline \multicolumn{8}{|l|}{$\mathrm{ED}$} \\
\hline Model 1 & 1 & $0.28(0.17-0.48)$ & $0.29(0.20-0.42)$ & $0.36(0.21-0.65)$ & $0.10(0.03-0.43)$ & $0.39(0.12-1.27)$ & 0.059 \\
\hline Model 2 & 1 & $0.30(0.17-0.50)$ & $0.28(0.19-0.41)$ & $0.40(0.22-0.71)$ & $0.14(0.03-0.56)$ & $0.73(0.22-2.39)$ & 0.100 \\
\hline Model 3 & 1 & $0.32(0.19-0.56)$ & $0.29(0.19-0.42)$ & $0.48(0.26-0.88)$ & $0.13(0.03-0.53)$ & $0.67(0.20-2.22)$ & 0.111 \\
\hline Model 4 & - & $0.50(0.13-1.94)$ & $0.45(0.12-1.68)$ & $0.77(0.19-3.20)$ & $0.20(0.03-1.25)$ & 1 & 0.063 \\
\hline Model 5 & - & $0.53(0.13-2.06)$ & $0.49(0.13-1.85)$ & $0.85(0.20-3.63)$ & $0.21(0.03-1.32)$ & 1 & 0.064 \\
\hline \multicolumn{8}{|l|}{$\mathrm{BD}$} \\
\hline Model 1 & 1 & $0.52(0.38-0.71)$ & $0.44(0.35-0.56)$ & $0.75(0.54-1.05)$ & $0.50(0.30-0.83)$ & $1.69(0.95-2.99)$ & 0.032 \\
\hline Model 2 & 1 & $0.49(0.36-0.68)$ & $0.46(0.36-0.58)$ & $0.75(0.54-1.06)$ & $0.36(0.22-0.61)$ & $0.88(0.49-1.59)$ & 0.124 \\
\hline Model 3 & 1 & $0.40(0.29-0.56)$ & $0.37(0.29-0.48)$ & $0.51(0.35-0.74)$ & $0.32(0.19-0.54)$ & $0.74(0.40-1.34)$ & 0.138 \\
\hline Model 4 & - & $0.41(0.21-0.81)$ & $0.36(0.19-0.69)$ & $0.52(0.25-1.08)$ & $0.38(0.18-0.83)$ & 1 & 0.076 \\
\hline Model 5 & - & $0.41(0.21-0.82)$ & $0.36(0.19-0.71)$ & $0.53(0.25-1.12)$ & $0.38(0.18-0.83)$ & 1 & 0.076 \\
\hline \multicolumn{8}{|l|}{$\mathrm{AD}$} \\
\hline Model 1 & 1 & $0.41(0.29-0.59)$ & $0.38(0.29-0.49)$ & $0.73(0.51-1.04)$ & $0.45(0.26-0.80)$ & $1.30(0.70-2.42)$ & 0.040 \\
\hline Model 2 & 1 & $0.40(0.28-0.57)$ & $0.39(0.30-0.51)$ & $0.72(0.51-1.03)$ & $0.38(0.21-0.66)$ & $0.87(0.46-1.63)$ & 0.072 \\
\hline Model 3 & 1 & $0.36(0.25-0.52)$ & $0.32(0.24-0.42)$ & $0.62(0.42-0.91)$ & $0.33(0.19-0.59)$ & $0.74(0.39-1.40)$ & 0.092 \\
\hline Model 4 & - & $0.44(0.21-0.91)$ & $0.41(0.20-0.83)$ & $0.81(0.37-1.80)$ & $0.44(0.19-1.03)$ & 1 & 0.070 \\
\hline Model 5 & - & $0.48(0.23-1.00)$ & $0.47(0.23-0.96)$ & $0.97(0.43-2.18)$ & $0.46(0.20-1.09)$ & 1 & 0.079 \\
\hline
\end{tabular}

In bold: statistically significant OR.

Model 1: crude model (Dutch = reference group); Model 2: adjusted for gender (total sample only) and age (Dutch = reference group); Model 3: as model 2, but also adjusted for marital status, education and employment (Dutch = reference group); Model 4: as model 3, but also adjusted for religiosity, migration and perceived ethnic discrimination (Dutch omitted, Moroccan = reference group); Model 5: as model 4, but also adjusted for depressed mood (Dutch omitted, Moroccan $=$ reference group).

$\mathrm{ED}$, excessive drinking; $\mathrm{BD}$, binge drinking; $\mathrm{AD}$, alcohol dependence. 
drinking is some 3 times higher in the Turkish than in the Moroccan ethnic minority group, but regular drinkers of Moroccan origin show a higher rate of excessive drinking, binge drinking and $\mathrm{AD}$ compared to their Turkish peers.

It is of interest that regular drinkers of Moroccan origin have a significantly higher risk to develop binge drinking and $\mathrm{AD}$ than regular drinkers in the other 4 ethnic minority groups. At the same time (after adjustment for confounders) regular drinkers of Moroccan origin have a similar risk for binge drinking and $\mathrm{AD}$ compared to their Dutch peers. These findings partially confirm previous findings, which showed that the rate of excessive drinking and AD was relatively high among Turkish and Moroccan ethnic minority groups compared to those of Dutch origin [12, 31]. Moreover, Dutch residents of Moroccan origin previously showed a threefold higher excessive alcohol use than their Turkish peers [13, 14].

Typical for people of Moroccan origin is their Muslim belief, which also applies, although to a lesser extent, to those of Turkish origin. For Muslims alcohol use is strictly forbidden and socially unacceptable (haram). In addition, Islamic principles teach preservation and protection of dignity of man, and steering mankind away from harm and destruction [32]. Accordingly, subjects with problematic alcohol use deny and disavow their problem, feel uncomfortable talking about it and are reluctant to seek treatment. On this basis, we hypothesized that alcohol use would lead more rapidly to problematic drinking (and $\mathrm{AD}$ ) in a Muslim environment as compared with social environments where drinking is the norm (e.g., among the Dutch). Recent data from Iran largely endorse this hypothesis as they showed a high incidence of AUD (1.3\%) along with a very low rate of alcohol consumption of 5.7\% [33]. No recent Dutch data are available about treatment of AD among specific ethnic minority groups, like Moroccans or Turks, because from 1994 ethnicity in the surveys is collectively stratified as patients with a native, western or non-western immigrant background. The latest figures available about treatment rates of $\mathrm{AD}$ across specific ethnic minority groups in the Netherlands are from 1993. Taking the Dutch as reference (the Dutch set as 1.0), the treatment rate of $\mathrm{AD}$ in residents of Moroccan origin is 0.7 (corrected for their share in the total population), which is relatively high considering their 12 -fold lower prevalence of alcohol consumption [34].

According to our hypothesis, present data show that regular drinkers of Moroccan origin - in contrast to those in other ethnic minorities - have an increased risk to de- velop $\mathrm{AD}$, but this was not explained by differences in religiosity, migration generation, PED, depressed mood or higher feelings of guilt and remorse around problematic alcohol use. In addition, regular drinkers of Turkish origin showed no higher risk for AD compared to their Dutch peers. Our hypothesis is therefore refuted, and the reason of this discrepancy remains to be resolved.

The current study has both strengths and limitations. The most important strengths are the broad range of different ethnic minorities, the large sample sizes, the use of standardized assessments and the availability of many potential confounders. The study also has some limitations. First, the study was cross-sectional and therefore we refrained from causal statements. Second, non-response was relatively high considering a response rate of $28 \%$. However, non-response analyses have shown that demographic and socioeconomic differences between participants and non-participants were very small [25]. Moreover, all ethnic group comparisons in the current study were controlled for a broad range of potential confounders. Finally, our study only used self-report questionnaires and no data were collected with (semi-) structured interviews or data provided by informants. However, the AUDIT has been shown considerable cross-culturally validity for the diagnosis of $\mathrm{AD}$, including European, African, South-American, and Asian populations (e.g., [35-37]), including studies with a Turkish and an Arabic version of the AUDIT [38, 39]. It should be noted, however, that the high prevalence rates of $\mathrm{AD}$ in this (and in other) studies does not necessarily indicate the presence of a high prevalence of chronic alcohol use disorders, since AD in a general population sample shows high rates of (spontaneous) remission (e.g., [40, 41]).

\section{Conclusion}

The differences between the Dutch and the ethnic groups with respect to the prevalence of regular drinking are considerably bigger than for current drinking. Based on the prevalence data, we conclude that, compared to the Dutch, the magnitude of problematic alcohol use is smaller in ethnic minorities in Amsterdam than in the ethnic Dutch population in Amsterdam. This includes male participants of Moroccan origin who showed a similar risk as their Dutch peers to become alcohol dependent when they regularly drink, but given their low rate of regular drinking the prevalence of $\mathrm{AD}$ is still very low compared to the their Dutch peers (Moroccans: 48.9\% AD among van Amsterdam et al. 
$4.1 \%$ regular drinkers $=2.0 \%$; Dutch: $30.9 \% \mathrm{AD}$ among $81.4 \%$ regular drinkers $=25.2 \%)$. Moreover, the other 4 minority groups were also less often regular drinkers than the Dutch and on top of that they showed a lower risk of $\mathrm{AD}$ compared to their Dutch peers. We were unable to provide an explanation for the high risk of regular drinkers of Moroccan origin to develop AD. However, we do know now that these differences are not explained by religiosity, migration generation, PED, depressed mood or higher feelings of guilt and remorse around problematic alcohol use.

\section{Acknowledgements}

The HELIUS study is conducted by the Academic Medical Center Amsterdam and the Public Health Service of Amsterdam. Both organizations provided core support for HELIUS. The HELIUS study is also funded by the Dutch Heart Foundation, the Netherlands Organization for Health Research and Development (ZonMw), the European Union (FP-7) and the European Fund for the Integration of non-EU immigrants. We gratefully acknowledge the AMC Biobank for their support in biobank management and high-quality storage of collected samples. We are most grateful to the participants of the HELIUS study and the management team, research nurses, interviewers, research assistants and other staff who have taken part in gathering the data of this study.

\section{Statement of Ethics}

The study protocol was approved by the Medical Ethical Review Board of the Academic Medical Center, University of Amsterdam, Amsterdam, the Netherlands.

\section{Disclosure Statement}

All authors declared no conflict of interest.

\section{Funding Sources}

The HELIUS study is conducted by the Academic Medical Center and the Public Health Service of Amsterdam. Both organizations provided core support for the study. The HELIUS study is also funded by the Dutch Heart Foundation (Hartstichting), The Netherlands Organization for Health Research and Development (ZonMw), the European Union, and the European Fund for the Integration of non-EU immigrants.

\section{Author Contributions}

J.G.C.A. was the main investigator and drafted the manuscript and A.B. performed the data analysis. The other co-authors (S.B., M.B.S., A.L., A.H.S., E.M.D., and W.B.) critically commented during drafting of the manuscript.

\section{References}

1 Bennett GG, Wolin KY, Robinson EL, Fowler S, Edwards CL. Perceived racial/ethnic harassment and tobacco use among African American young adults. Am J Public Health. $2005 \mathrm{Feb} ; 95(2): 238-40$.

2 Landrine H, Klonoff EA, Corral I, Fernandez S, Roesch S. Conceptualizing and measuring ethnic discrimination in health research. J Behav Med. 2006 Feb;29(1):79-94.

3 Borrell LN, Jacobs DR Jr, Williams DR, Pletcher MJ, Houston TK, Kiefe CI. Self-reported racial discrimination and substance use in the Coronary Artery Risk Development in Adults Study. Am J Epidemiol. 2007 Nov; 166(9):1068-79.

4 Borrell LN, Diez Roux AV, Jacobs DR Jr, Shea S, Jackson SA, Shrager S, et al. Perceived racial/ethnic discrimination, smoking and alcohol consumption in the Multi-Ethnic Study of Atherosclerosis (MESA). Prev Med. 2010 Sep-Oct;51(3-4):307-12.

5 Chae DH, Takeuchi DT, Barbeau EM, Bennett GG, Lindsey JC, Stoddard AM, et al. Alcohol disorders among Asian Americans: associations with unfair treatment, racial/ethnic discrimination, and ethnic identification (the national Latino and Asian Americans study,
2002-2003). J Epidemiol Community Health. 2008 Nov;62(11):973-9.

6 Gee GC, Delva J, Takeuchi DT. Relationships between self-reported unfair treatment and prescription medication use, illicit drug use, and alcohol dependence among Filipino Americans. Am J Public Health. 2007 May; 97(5):933-40.

7 Terrell F, Miller AR, Foster K, Watkins CE Jr. Racial discrimination-induced anger and alcohol use among black adolescents. Adolescence. 2006;41(163):485-92.

8 Gilbert PA, Zemore SE. Discrimination and drinking: A systematic review of the evidence. Soc Sci Med. 2016 Jul;161:178-94.

9 Ikram UZ, Snijder MB, Fassaert TJ, Schene $\mathrm{AH}$, Kunst AE, Stronks K. The contribution of perceived ethnic discrimination to the prevalence of depression. Eur J Public Health. 2015 Apr;25(2):243-8.

10 Ikram UZ, Snijder MB, de Wit MA, Schene AH, Stronks K, Kunst AE. Perceived ethnic discrimination and depressive symptoms: the buffering effects of ethnic identity, religion and ethnic social network. Soc Psychiatry Psychiatr Epidemiol. 2016 May;51(5):67988.
11 Zick A, Wolf C, Küpper B, Davidov E, Schmidt P, Heitmeyer W. The syndrome of group-focused enmity: the interrelation of prejudices tested with multiple cross-sectional and panel data. J Soc Issues. 2008;64(2): 363-83.

12 Visser MJ, Ikram UZ, Derks EM, Snijder MB, Kunst AE. Perceived ethnic discrimination in relation to smoking and alcohol consumption in ethnic minority groups in The Netherlands: the HELIUS study. Int J Public Health. 2017 Nov;62(8):879-87.

13 Dotinga A. 'Drinking in a dry culture'. Alcohol use among second-generation Turks and Moroccans: measurements and results. Thesis Rotterdam University 2005. Available from: http://repub.eur.nl/pub/6972/051006_ Dotinga-A.pdf.

14 Dotinga A, van den Eijnden JJ, Bosveld W, Garretsen HF. Religious, cultural and social cognitive correlates of alcohol use among Turks and Moroccans in The Netherlands. Addict Res Theory. 2006;14(4):413-31.

15 Ransome Y, Gilman SE. The Role of Religious Involvement in Black-White Differences in Alcohol Use Disorders. J Stud Alcohol Drugs. 2016 Sep;77(5):792-801. 
16 Meyers JL, Brown Q, Grant BF, Hasin D. Religiosity, race/ethnicity, and alcohol use behaviors in the United States. Psychol Med. 2017 Jan;47(1):103-14.

17 Ramstedt M. Alcohol and suicide in 14 European countries. Addiction. 2001 Feb;96(Suppl 1):S59-75.

18 Cherpitel CJ, Bond J, Ye Y, Borges G, MacDonald S, Stockwell T, et al. Alcohol-related injury in the ER: a cross-national meta-analysis from the Emergency Room Collaborative Alcohol Analysis Project (ERCAAP). J Stud Alcohol. 2003 Sep;64(5):641-9.

19 Mulia N, Ye Y, Greenfield TK, Zemore SE. Disparities in alcohol-related problems among white, black, and Hispanic Americans. Alcohol Clin Exp Res. 2009 Apr;33(4):65462.

20 Witbrodt J, Mulia N, Zemore SE, Kerr WC. Racial/ethnic disparities in alcohol-related problems: differences by gender and level of heavy drinking. Alcohol Clin Exp Res. 2014 Jun;38(6):1662-70.

21 Mulia N, Tam TW, Bond J, Zemore SE, Li L. Racial/ethnic differences in life-course heavy drinking from adolescence to midlife. J Ethn Subst Abuse. 2018 Apr-Jun;17(2):167-86.

22 Grant JD, Vergés A, Jackson KM, Trull TJ, Sher KJ, Bucholz KK. Age and ethnic differences in the onset, persistence and recurrence of alcohol use disorder. Addiction. 2012 Apr; 107(4):756-65

23 Evans EA, Grella CE, Washington DL, Upchurch DM. Gender and race/ethnic differences in the persistence of alcohol, drug, and poly-substance use disorders. Drug Alcohol Depend. 2017 May;174:128-36.

24 Stronks K, Snijder MB, Peters RJ, Prins M, Schene AH, Zwinderman AH. Unravelling the impact of ethnicity on health in Europe: the HELIUS study. BMC Public Health. 2013 Apr;13(1):402-12.

25 Snijder MB, Galenkamp H, Prins M, Derks EM, Peters RJ, Zwinderman AH, et al. Cohort profile: the Healthy Life in an Urban Setting
(HELIUS) study in Amsterdam, The Netherlands. BMJ Open. 2017 Dec;7(12):e017873.

26 Stronks K, Kulu-Glasgow I, Agyemang C. The utility of 'country of birth' for the classification of ethnic groups in health research: the Dutch experience. Ethn Health. 2009 Jun; 14(3):255-69.

27 de Graaf R, Have M, van Dorsselaer S. De psychische gezondheid van de Nederlandse bevolking. Nemesis-2: opzet en eerste resultaten. Utrecht, The Netherlands: Netherlands Institute of Mental Health and Addiction; 2010., Available from https://assets-sites.trimbos. nl/docs/9b912526-eb91-464f-87fa-2e064cee 197a.pdf.

28 Babor TF, Higgins-Biddle JC, Saunders JB, Monteiro MG. The Alcohol Use Disorders Identification Test. Guidelines for Use in Primary Care. Second Edition; WHO report 2001. Available from: http://whqlibdoc.who. int/hq/2001/who msd msb 01.6a.pdf.

29 Saunders JB, Aasland OG, Babor TF, de la Fuente JR, Grant M. Development of the Alcohol Use Disorders Identification Test (AUDIT): WHO Collaborative Project on Early Detection of Persons with Harmful Alcohol Consumption-II. Addiction. 1993 Jun;88(6): 791-804.

30 Gee GC, Ro A, Shariff-Marco S, Chae D. Racial discrimination and health among Asian Americans: evidence, assessment, and directions for future research. Epidemiol Rev. 2009;31(1):130-51.

31 Dotinga A, van den Eijnden JJ, Bosveld W, Garretsen HF. Abstaining, excessive drinking, binge drinking, and help-seeking behavior among Turks in the Netherlands. J Soc Work Pract Addict. 2008;8(1):44-64.

32 Kamarulzaman A, Saifuddeen SM. Islam and harm reduction. Int J Drug Policy. 2010 Mar; 21(2):115-8.

33 Amin-Esmaeili M, Rahimi-Movaghar A, Sharifi V, Hajebi A, Mojtabai R, Radgoodarzi $\mathrm{R}$, et al. Alcohol use disorders in Iran: Prevalence, symptoms, correlates, and comorbidi- ty. Drug Alcohol Depend. 2017 Jul;176:4854.

34 Braam RV, Verbraeck HT, van de Wijngaart $\mathrm{GF}$. Allochtonen en verslaving. Centrum voor Verslavingsonderzoek, University of Utrecht, Utrecht, The Netherlands 1998. Available from: https://www.drugresearch.nl/index. $\mathrm{php} /$ lijst/overigen/allochtonen-en-verslaving/download.

35 Li Q, Babor TF, Hao W, Chen X. The Chinese translations of Alcohol Use Disorders Identification Test (AUDIT) in China: a systematic review. Alcohol Alcohol. 2011 Jul-Aug;46(4): 416-23.

36 Moretti-Pires RO, Corradi-Webster CM. [Adaptation and validation of the Alcohol Use Disorders Identification Test (AUDIT) for a river population in the Brazilian Amazon]. Cad Saude Publica. 2011 Mar;27(3): 497-509.

37 Vissoci JR, Hertz J, El-Gabri D, Andrade Do Nascimento JR, Pestillo De Oliveira L, Mmbaga BT, et al. Cross-Cultural Adaptation and Psychometric Properties of the AUDIT and CAGE Questionnaires in Tanzanian Swahili for a Traumatic Brain Injury Population. Alcohol Alcohol. 2018 Jan;53(1):112-20.

38 AlMarri TS, Oei TP, Amir T. Validation of the alcohol use identification test in a prison sample living in the Arabian Gulf region. Subst Use Misuse. 2009;44(14):2001-13.

39 Gül S, Akvardar Y, Taș G, Tuncel P. [The diagnostic validity of screening tests and laboratory markers in alcohol use disorders]. Turk Psikiyatr Derg. 2005 Spring;16(1):3-12.

40 Dawson DA, Grant BF, Stinson FS, Chou PS, Huang B, Ruan WJ. Recovery from DSM-IV alcohol dependence: united States, 20012002. Addiction. 2005 Mar;100(3):281-92.

41 de Bruijn C, van den Brink W, de Graaf R, Vollebergh WA. The three year course of alcohol use disorders in the general population: DSM-IV, ICD-10 and the Craving Withdrawal Model. Addiction. 2006 Mar;101(3):38592. 